\title{
New model for agricultural countermeasures in RODOS and ARGOS
}

\author{
F. GERING ${ }^{1}$, W. RASKOB ${ }^{2}$, T. CHARNOCK $^{3}$
}

\begin{abstract}
Predictions of the effects of agricultural countermeasures are an important part of the decision-making process following an accidental release of radioactive material into the environment. A new model has been developed for this purpose and integrated into the EU decision support systems RODOS and ARGOS. The model is based on the existing food chain model of RODOS and the previous model for simulating agricultural countermeasures in RODOS. The characteristics of the countermeasures and the supporting databases have been derived from the compendia and handbooks developed within the EURANOS project. A wide range of potentially practicable countermeasures is considered on timescales from a day to many years, and endpoints related to their imposition are calculated such that the economic and health impacts can be evaluated. This paper outlines the countermeasures methodology adopted and the databases used and discusses their applicability.
\end{abstract}

\section{Introduction}

Predictions of the effects of agricultural countermeasures are an important part of the decision-making process following an accidental release of radioactive material into the environment. The European decision support system RODOS (real-time on-line decisions support (Ehrhardt and Weis, 2000; Ehrhardt and Raskob, 2007)) has for many years included a model for simulating the effects of agricultural countermeasures (Brown et al., 1997), which has been developed by the Health Protection Agency, UK. Limitations of this well-accepted model only became obvious when new countermeasures were to be implemented. Within the EURANOS (Raskob et al., 2010) project it was decided to replace the old countermeasure model by a new model named AGRICP (AGRIcultural Countermeasure Program). The new model provides a much higher flexibility in defining countermeasures and countermeasure strategies than any model realised so far. This has been achieved by integrating the countermeasure simulation engine into the physical modelling complex of the existing food chain model (Müller and Bleher, 1997) of RODOS. The full functionality of the previous model has been kept within the new AGRICP model. Wherever possible, model

\footnotetext{
Bundesamt für Strahlenschutz, München-Neuherberg, Germany.

Karlsruhe Institute of Technology, Institut für Kern- und Energietechnik, Eggenstein-Leopoldshafen, Germany

Health Protection Agency, Centre for Radiation, Chemical and Environmental Hazards, Chilton, Didcot, UK.
} 
approaches (e.g. for worker dose calculation) were taken over from the previous countermeasure module. As a new feature, feedback of an agricultural countermeasure on the estimation of the radiological situation has been realised (e.g. increasing contamination of feed and foodstuffs through spreading of contaminated products like milk in the agricultural areas). This required a recalculation of the activity contamination once the countermeasure is selected. Having implemented such an option in AGRICP, means that the assessment of waste options will be possible for some foods in future. One of the objectives in the new development was to allow for the implementation of additional countermeasures which emerged within the EURANOS project from work on the generic handbook for management of contaminated food production systems in Europe (Nisbet et al., 2009). Not all countermeasures collected in (Nisbet et al., 2009) were explicitly modelled, since several options only have effects outside the scope of radioecological modelling (or depend on local variability of soil contamination, which can not be modelled adequately). One further objective of the project, realised at the end of EURANOS, was to integrate the new agricultural countermeasure model in both European decision support systems RODOS (Ehrhardt and Weis, 2000; Ehrhardt and Raskob, 2007) and ARGOS (Hoe et al., 2008).

\section{Modelling approach}

Food countermeasures may be implemented as early as a few days after the contamination occurred and may last over long periods of time. The exposure pathways of importance during these time periods are external exposure from deposited activity, inhalation of resuspended material and ingestion of contaminated food. The restriction of food is intended to protect against the last of these. The agricultural countermeasure model presented here is designed to investigate - as early as possible - countermeasure options that could be effective in reducing activity concentrations in food and so reduce the severity of food restrictions.

The initial aim of modelling agricultural countermeasures is to determine if there is a need for intervention, i.e. whether there is a need for implementation of food restrictions based on user supplied criteria. As a default, the EC maximum permitted levels of radioactive contamination of foodstuffs (Council Regulation, 1987) are used, although the user of the model can change these criteria. The predicted activity concentrations in food are compared with the criteria as a function of time, nuclide and spatial position. If intervention is required, the aim is to provide the information about how countermeasures could reduce the duration and extent of food restrictions. For comparison of different countermeasure 
strategies it is also relevant to know more about the effects of these management options, e.g. the costs, the resources required, the waste produced, the doses saved and the resulting doses to workers.

The agricultural countermeasure model operates in two modes. First it allows early screening of possible strategies, identifying those which may be effective and worthy of further investigation, and also dismissal of other options. Second, more complex management options can be defined within a particular countermeasure strategy. The early screening mode is a valuable part of a decision support system since it allows the decision maker to focus on those options most likely to be of benefit.

The agricultural countermeasure model has been realised by introducing new features for countermeasure simulation into the food chain model of RODOS (Müller and Bleher, 1997), which is itself based on the radioecological model ECOSYS-87 (Müller and Pröhl, 1993), but which has been adapted and further developed during the past 15 years. Implementing countermeasure options directly into the food chain calculations seemed to be the optimum solution to achieve flexibility and consistency as any strategy selected will directly interact with the computational kernel of the food chain modelling. Whereas the previous approach was restricted, for example it could only handle a few pre-calculated application times. To this purpose, a database had to be developed identifying the parameters to be modified for each of the countermeasure options implemented. Modification factors for each countermeasure had to be derived from the effectiveness factors for particular countermeasures in the previous model approach.

The agricultural countermeasures considered can be found in Table I, together with the main parameters of the food chain model that are affected by each countermeasure. The foods considered both in the food chain model and the countermeasure modelling are listed in Table II. Not all countermeasures from Table I can be applied to all foods from Table II, for example the option "Amelioration" is only available for food products based on crops (like wheat, rye, oats, etc.).

Brief descriptions of each countermeasure option included are given below. Parameters such as the timing of the implementation of an option or the duration of a countermeasure can be changed by the user so that a range of possible scenarios can be considered.

(1) In most countries, food above the criterion has to be disposed of and will not enter the food chain for consumption. This legal constraint implicitly assumes that each option is accompanied by the disposal option if predicted activity 


\section{TABLE I}

Agricultural countermeasures considered in the model.

\begin{tabular}{|c|c|}
\hline Countermeasure option & Main parameter modification in countermeasure model \\
\hline Doing nothing & - Reference run - \\
\hline Stopping production & $\begin{array}{l}\text { No modification necessary. Food production stops for the user-selected } \\
\text { time }\end{array}$ \\
\hline Food processing & Processing factors of radioecological model are used \\
\hline Storing food & Processing and delay times of radioecological model are modified \\
\hline $\begin{array}{l}\text { Removing animals from } \\
\text { contaminated feed }\end{array}$ & $\begin{array}{l}\text { Concentration in all feed / parts of feed will be set to zero for a given time } \\
\text { interval }\end{array}$ \\
\hline $\begin{array}{l}\text { Substituting of animals feed with } \\
\text { other contaminated feeds }\end{array}$ & Modification of the animal's diet necessary \\
\hline Addition of sorbents & Transfer factor animal - animal product \\
\hline Amelioration / soil improvement & Transfer factor soil - crop \\
\hline Change in land use & No modification necessary \\
\hline Change of crop species & No modification necessary \\
\hline Decontamination of agricultural land & Reduced contamination from time of ploughing \\
\hline $\begin{array}{l}\text { Spreading of contaminated milk / } \\
\text { composting on agricultural land }\end{array}$ & Recalculation of food contamination with additional contamination in soil \\
\hline Early removal of crops & $\begin{array}{l}\text { Reduced contamination in the soil (effective for crops grown in } \\
\text { subsequent years) }\end{array}$ \\
\hline Manipulation of slaughter times & $\begin{array}{l}\text { Prolonged fattening period, identification of seasonal variation of meat } \\
\text { contamination }\end{array}$ \\
\hline Ploughing in of a standing crop & Increased contamination from time of ploughing \\
\hline
\end{tabular}

TABLE II

Foods considered in the agricultural countermeasure model.

\begin{tabular}{lll}
\hline & \multicolumn{1}{c}{ Foods } & \\
\hline spring wheat (whole) & leafy vegetables & goat's milk \\
spring wheat (flour) & root vegetables & sheep's milk \\
spring wheat (bran) & fruit vegetables & beef (cow) \\
winter wheat (whole) & fruits & beef (bull) \\
winter wheat (flour) & berries & veal \\
winter wheat (bran) & cow's milk & pork \\
rye (whole) & condensed milk & lamb \\
rye (flour) & cream & chicken \\
\hline rye (bran) & butter & roe deer \\
\hline oats & cheese (rennet) & eggs \\
\hline potatoes & cheese (acid) & beer \\
\hline
\end{tabular}


concentrations in food are above the maximum permitted levels. In this respect disposal is not a separate countermeasure option, but may still be necessary after implementation of certain countermeasures. It is assumed that disposal is continued for the duration that the activity concentrations exceed the criteria and that the quantities of disposed food are calculated.

(2) Stopping of food production: the user can choose at what time following the accident she/he wishes to consider that a particular crop is no longer grown or a food/food product no longer produced. This option can include immediate slaughter, slaughtering of dairy livestock (might be chosen if, for example, the period of lost production is too long) and suppression of lactation before slaughter. Stopping of food production is an option to reduce waste, i.e. the amount of contaminated foods requiring disposal.

(3) Food processing is only considered for cows' milk (processing into butter, cheese, cream, condensed milk) and whole wheat (processing of summer wheat, winter wheat and rye into flour and bran). For other foods the only processing options are freezing or canning, which will not significantly change the activity concentrations in the food, but the possible storage times become much larger. Thus for these processing options only the effect of storage has to be considered. Food processing is modelled under the assumption that there are no differences between processing as a countermeasure and processing under normal conditions. Delays between production of the raw food and consumption of the processed food are included.

(4) Storage of food can reduce the activity concentrations significantly for shortlived nuclides such as ${ }^{131}$ I. Storage on its own is only considered for wheat and for milk stored as milk products (butter, cheese, cream and condensed milk) via normal processing procedures. Processing followed by storage will be considered for all other fresh foods that cannot be stored in their fresh form without perishing but can be processed, i.e. canned, dried or frozen. The assumption is made that no activity concentration is lost due to this processing procedure. The user can choose two storage times for fresh and processed foods.

(5) Removing animals from contaminated feed can either represent the removal of animals from contaminated pasture (including short term sheltering of dairy animals) or the substitution of contaminated feed with uncontaminated feed (or other contaminated feed). Various parameters can be chosen including the start and time span of administering clean feed, the proportion of clean and contaminated feed in the diet, and the use of different feedstuffs. In the EURANOS handbook (Nisbet et al., 2009) short-term sheltering of dairy animals is distinguished from long-term clean feeding/housing of livestock as short-term sheltering is implemented prior to deposition and 
feeding is done only with stored feedstuffs. Both variants are modelled in the same way in AGRICP.

(6) Administration of sorbents includes adding sorbents to animal feedstuffs, adding it directly to the animal's gut in the form of boli or adding sorbents to saltlicks. Sorbents that can be considered are clay minerals (e.g. bentonite), AFCF (both for radiocaesium) and stable calcium (for strontium). These sorbents can be effective binders for particular radionuclides and can significantly reduce, for example, the contamination in milk or meat. The effectiveness of AFCF in saltlicks depends on the requirement of animals for additional salt. While sorbents in animal feedstuffs (e.g. in concentrate ration) would be administered daily, AFCF boli are administered every 2-3 months (for dairy animals) or 2-3 months prior to slaughter.

(7) Amelioration is the treatment of soils to improve their quality and reduce the uptake of radionuclides by plants. It is assumed that activity uptake by plants is reduced immediately following application, and that soil treatment is only effective for a given finite time span.

(8) Change of crop species means growing one crop or vegetable instead of the original crop with the purpose of reducing the contamination in the resulting foodstuff. The species that gives the lowest contamination is selected automatically. It is assumed that the crop change will be permanently continued following the implementation.

(9) Only one change of land use is considered, the change from agricultural production to forestry. It is assumed that the food production permanently stops after the implementation of this option.

(10) Decontamination of agricultural land by ploughing or top soil removal is considered with a robust approach, where it is assumed that ploughing or soil removal reduces the activity in the soil available to the plants (same reduction for all plants). Different reduction factors are assumed for the options skim and burial ploughing, deep ploughing and top soil removal.

(11) Some agricultural land is potentially suitable for the spreading of contaminated milk, either in conjunction with slurry or diluted with water. The objective of this measure is waste disposal rather than reducing contamination. As spreading of slurry is a normal agricultural practice, no special skills or equipment are required for this option, but the possible perception of causing additional contamination of the soil if milk/slurry is spread on farmland may be problematic. The same modelling approach is used for composting, where the targets are contaminated crops and grass waste..

(12) Early removal of crops and its disposal can be quite effective for reducing the contamination of arable land and its future products as radionuclides may be retained on the surface of growing crops immediately after fallout and the 
transfer of this contamination to the soil may be minimised by removing such crops from the land as soon as possible after deposition. This option is modelled by considering the dependence of the effectiveness of interception of radionuclides on the amount of biomass present at time of deposition and including the decrease of effectiveness with time passing between deposition and harvest.

(13) In the early to medium phase manipulation of slaughter times may be used to reduce activity concentrations in meat as a consequence of physical decay of short-lived radionuclides, or losses from the tissues (biological half-life) by adopting a prolonged fattening period. In the longer term seasonal variation in the radionuclide content of animals diets, and hence meat, may be exploited (i.e. slaughtering occurring at a time of year when the contamination levels are low); this option can be effective especially for sheep meat and reindeer.

(14) Ploughing in of a standing crop is the direct incorporation of crops into soil at any stage of development. Ploughing in destroys crops and removes them from the foodchain, thereby removing doses from ingestion. It also reduces the amount of contaminated foods requiring disposal. However as a sideeffect, the soil beneath the crop becomes more contaminated than it would otherwise be (depending on the interception of radionuclides in the biomass).

In some cases the user of the countermeasure model may be interested not only in the effect of single countermeasures, but may also wish to investigate combinations of countermeasures. One example of a practical combination of countermeasures is addition of sorbents to the diet of cows combined with processing of milk. The new model gives a high degree of flexibility for defining such combinations, e.g. the two measures mentioned above could start at different times (for example, the strategy starts with adding sorbents for one month, followed by processing starting at month 2). Combinations of more than two measures are possible, even though such combinations could be quite complex to achieve in practice. The model does not check whether a chosen combination is impracticable - this lies within the responsibility of the user, but it only allows each countermeasure to be applied for such foods where it is reasonable.

Contamination of animal products may occur from either ingestion of contaminated feeds or from inhalation whilst the radioactive plume is passing. The effects of inhalation by animals on the endpoints calculated by the model have been included for completeness to take into account situations where the products may be contaminated via the inhalation pathway while animals are not consuming contaminated feed. This situation might arise if the animals are indoors eating uncontaminated fodder while the plume passes. There are only a few countermeasures which are suggested in some emergency plans which can be undertaken in order to reduce the activity concentrations in animals resulting from 
inhalation of radionuclides. Moving the animals from the plume may or may not be practical, depending on the number of animals involved. Sheltering the animals "indoors" may or may not reduce the inhalation component, depending on how low the air exchange rates in the farm buildings are. However, none of the countermeasures currently considered in the agricultural countermeasure model would achieve reductions in activity concentrations resulting from inhalation of radionuclides. Therefore, within the agricultural countermeasure model a simple approach is used to consider the pathway of inhalation by animals: The activity concentrations in foods arising from animals inhaling are included in the activity concentrations compared with the ban criteria to see if any action is required. The only countermeasure that could prevent food contamination from animals inhaling is "stopping of food production". All other countermeasures affect only the contamination arising from ingestion of feeds, and thus have no effect on the food contamination from animals inhaling.

\section{Worker dose modelling}

The purpose of estimating worker doses is to indicate the scale of exposures to workers as one aspect for the comparison between different countermeasure options. The approach for estimating doses to workers involved in implementing countermeasures is described in this section. This functionality is available for all countermeasures considered in the agricultural countermeasure model described in this paper. Workers are those people involved in implementing countermeasures. The overall approach is to break down each of the countermeasures modelled into the individual tasks that they involve. For the estimation of worker doses the only tasks considered are those which are introduced solely as a result of the countermeasure. Doses arising from tasks that are expected to be carried out regardless of decisions on countermeasures are not considered (this is consistent with the approach for the EURANOS handbook for management of contaminated food production systems (Nisbet et al., 2009)). This approach requires that for each countermeasure those tasks which are considered to be solely applicable to the countermeasure and those tasks which are considered to be "routine" activities are separately identified. As a result, for some countermeasures worker doses are zero since all required tasks are part of normal farming practice (e.g. storage and processing, animal feeding with sorbents, changes to crops grown). Doses arising from waste disposal are not included as there are many different disposal routes and the routes chosen and the doses accrued would very much depend on local conditions such as, for example, drive times to a disposal facility.

Both collective and individual doses are calculated for workers. The approach to calculating individual and collective worker doses is different from that used for 
calculating doses for members of the public. Implementation of a countermeasure may require different tasks to be done, while the individual doses associated with each specific task could be rather different. The individual dose to a worker will depend on how long that worker is engaged upon the task and also whether the worker undertakes more than one task. The length of time for which a worker is engaged on a task depends on the times for starting and completion of the countermeasure (which can be entered by the user), as this information is used to determine the number of teams required. Workers undertaking more than one task are not explicitly modelled, rather the dose that is taken as individual worker dose is that which results from the one task leading to the highest exposure. The collective worker dose is a more robust quantity than the individual dose, as it is not sensitive to workers carrying out specific tasks within a countermeasure. To estimate the collective dose, individual doses for each task are calculated and summed over all the tasks and all workers required to implement the countermeasure.

The exposure pathways of relevance for workers depend on whether the countermeasures are carried out during the passage of the plume or after the plume has passed. Here the simplifying assumption is made that countermeasures would either be initiated after the plume has passed or that the work is finished before the plume arrives (e.g. for bringing animals indoors). Therefore, the main exposure pathways to be considered are external dose from the ground and inhalation dose from resuspension (which may be enhanced by the action of the task being undertaken). Worker doses are calculated for adults, and for effective dose only.

The modelling approach for worker doses can be summarised as following:

(1) For each countermeasure option considered, the tasks involved in implementing the countermeasure were identified (not including "routine" activities).

(2) For each task identified, the relevant exposure pathways were listed.

(3) Task/pathway combinations that can be modelled in a generic way were grouped together. Pathways that are expected to lead to small doses compared to others were removed.

(4) For each generic pathway group, a modelling approach was defined. Each approach took account of the approach adopted in the EURANOS handbook for management of contaminated food production systems (Nisbet et al., 2009).

(5) The sum of the doses (for collective dose) and the maximum dose (for individual dose) are calculated for each task within each countermeasure. 
TABLE III

Tasks and generic pathways for some countermeasures used in the worker dose modelling.

\begin{tabular}{|c|c|c|}
\hline Countermeasure & Task & Generic pathway \\
\hline \multirow{2}{*}{$\begin{array}{l}\text { Removing animals from contaminated } \\
\text { feed }\end{array}$} & Movement of animals & $\begin{array}{l}\text { External (outdoor/in vehicle) } \\
\text { Resuspension (outdoor/in vehicle) }\end{array}$ \\
\hline & $\begin{array}{l}\text { Management of animals } \\
\text { indoors }\end{array}$ & $\begin{array}{l}\text { External (outdoor/in vehicle) } \\
\text { Resuspension (outdoor/in vehicle) }\end{array}$ \\
\hline \multirow{2}{*}{$\begin{array}{l}\text { Amelioration / application of fertilisers } \\
\text { to land }\end{array}$} & $\begin{array}{l}\text { Management of agricultural } \\
\text { land }\end{array}$ & $\begin{array}{l}\text { External (outdoor/in vehicle) } \\
\text { Resuspension (outdoor/in vehicle) }\end{array}$ \\
\hline & Ploughing & $\begin{array}{l}\text { External (outdoor/in vehicle) } \\
\text { Resuspension (outdoor/in vehicle) }\end{array}$ \\
\hline $\begin{array}{l}\text { Decontamination of agricultural } \\
\text { land (ploughing) }\end{array}$ & Ploughing & $\begin{array}{l}\text { External (outdoor/in vehicle) } \\
\text { Resuspension (outdoor/in vehicle) }\end{array}$ \\
\hline
\end{tabular}

With the simplifications described above (mainly neglecting exposure during plume passage), only two generic pathway groups remain:

(1) External exposure (outdoor/in vehicle): includes external dose from activity deposited in the environment to workers outdoors and to workers implementing countermeasures whilst in vehicles e.g. tractors, lorries etc.

(2) Exposure from resuspension (outdoor/in vehicle): Includes resuspension dose both from activity deposited in the environment to workers outdoors and to workers implementing countermeasures whilst in vehicles. The effect of enhanced resuspension from the mechanical action of the vehicle can be considered.

In principle, the generic pathway groups "External exposure (indoor)" and "Exposure from resuspension (indoor)" could be also considered, but for agricultural countermeasures the distinction between indoor and outdoor exposure does not make much sense, since for typical farm buildings shielding effects should be negligible. The effects of personal protective equipment - reduction of dose from resuspension, but also decreased work-rates - can be modelled if requested. Table III shows tasks and generic pathways groups for some example countermeasures.

\section{Implementation and operation}

The new agricultural countermeasure model has been integrated within both European decision support systems RODOS and ARGOS, with differences mainly in the user interfaces and the mode of operation. In ARGOS two modes of operation exist for the agricultural countermeasure model: 1) a manual mode, 


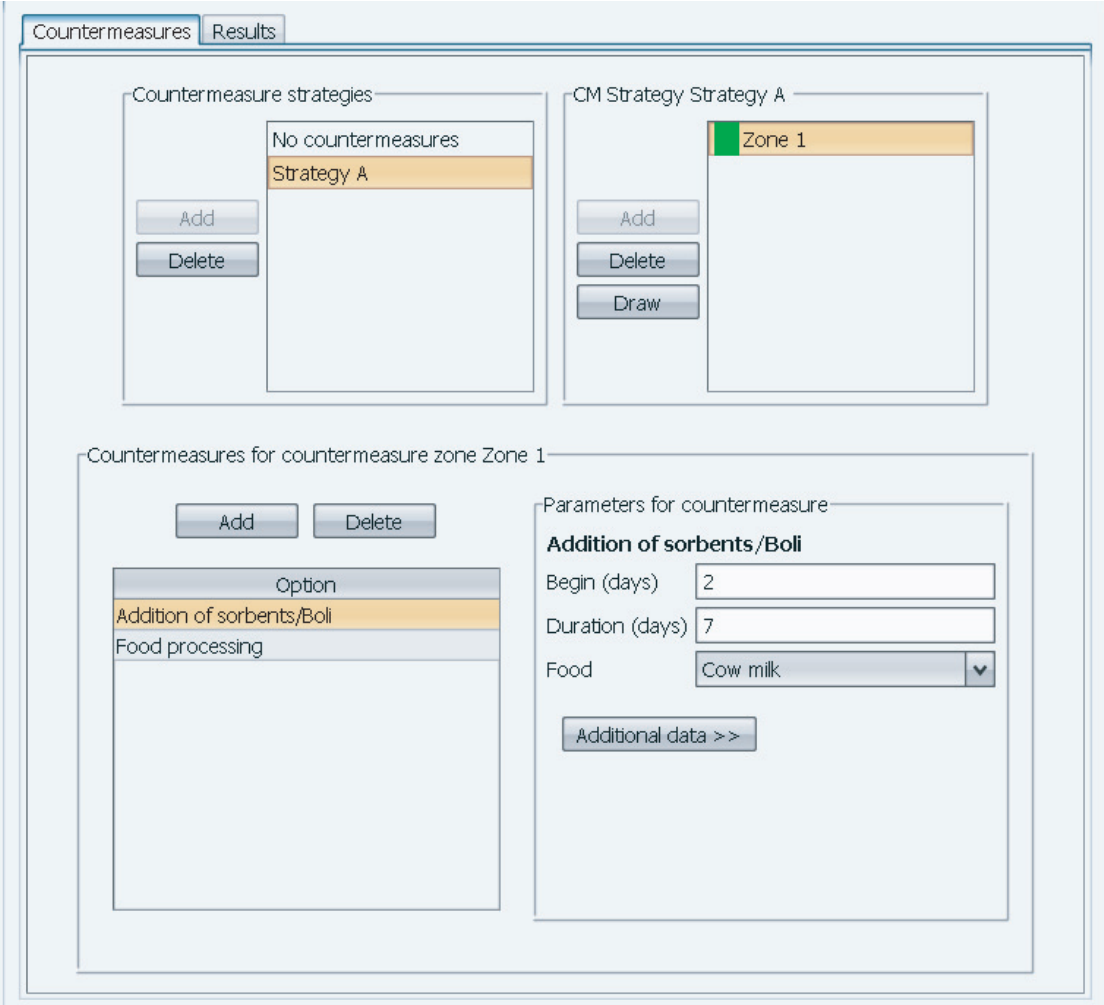

Figure 1 - Graphical user interface of the agricultural countermeasure model in RODOS.

where a single "run" either produces a map layer to be overlaid on the normal ARGOS map or a chart dataset (histogram/pie chart/line chart) to be shown in a separate window; and 2) an automatic mode, where a "screening" function categorises all affected municipalities into groups (portfolios). In RODOS only an interactive/manual mode of operation exists, in which the user defines a countermeasure strategy via a graphical user interface and then starts a model run to calculate the effects of the chosen strategy. A screenshot of the graphical user interface in RODOS is shown in Figure 1; in this window the user can define a countermeasure strategy by selecting one countermeasure or a combination of countermeasures - together with the corresponding parameters such as start and duration - within zones. A zone defines an area where the same countermeasures with the same parameters are being applied. Such zones can be defined graphically within the GIS (Geographic information system) component of the system. A strategy can include more than one zone, i.e. one strategy can include several areas 
("zones") where different countermeasures are applied. The "no countermeasure" strategy is always calculated in parallel for comparison.

Within the agricultural countermeasure model, several endpoints related to the imposition of countermeasures on food are evaluated. All endpoints are calculated for the "no countermeasure" option as reference and for all (one or more) countermeasure strategies chosen by the user. A countermeasure strategy is defined mainly by a selection of one or more countermeasures, and the area of implementation and the timing for each of these countermeasures. In the following all endpoints are listed (units in brackets):

(1) Countermeasure(s) selected.

(2) Food contamination $(\mathrm{Bq} / \mathrm{kg})$.

(3) Food above intervention level $(\mathrm{kg})$ :

The amount of food above the intervention level is calculated by comparison of the time dependent results for food contamination with the appropriate intervention level (for each food and nuclide group separately). If the intervention level is exceeded in a time interval, the food production for this time interval is added to the total amount of food above the intervention level. For a rough estimation of waste quantities, all food being produced with activity concentrations above the intervention levels can be treated as waste. For the option of stopping of food production only it is assumed that no food products are generated and therefore no foods above the intervention level and no waste can occur for this option (as such this option allows for the reduction of waste). Additional waste, which could occur from decontamination of agricultural areas (e.g. if top soil is removed) is not considered in this approach.

(4) Ban duration (days):

The duration of a ban is calculated by comparison of the time dependent results for food contamination with the appropriate intervention level. Only discrete modelling time steps are considered here. All time steps where the food contamination for at least one nuclide group is above the intervention level are accounted for the total ban duration.

(5) Ban area $\left(\mathrm{km}^{2}\right)$.

(6) Individual ingestion dose $(\mathrm{mSv})$.

(7) Collective ingestion dose (man $\mathrm{mSv}$ ).

(8) Averted individual dose $(\mathrm{mSv})$ :

The model does not provide any doses to the public other than the dose from ingestion, therefore averted doses consider only the ingestion pathway. Averted doses are derived from the difference of the doses for the "no countermeasure" option and the doses for the given countermeasure strategy.

(9) Averted collective dose (man $\mathrm{mSv}$ ). 
TABLE IV

Resource endpoints calculated in the countermeasure model.

\begin{tabular}{ll}
\hline Countermeasure option & Description of resource endpoint \\
\hline Stopping production & None \\
\hline Food processing & Total amount of food requiring processing $(\mathrm{kg})$ \\
\hline Storing food & Maximum amount of food stored $(\mathrm{kg})$ \\
\hline Removal of animals from contaminated feed & Total uncontaminated feed required $(\mathrm{kg})$ \\
\hline Substituting of animals feed & Total replacement feed required $(\mathrm{kg})$ \\
\hline Addition of sorbents & Total sorbents required $(\mathrm{kg})$ \\
\hline Amelioration / soil improvement & Total ameliorants required $(\mathrm{kg})$ \\
\hline Change in land use & Total land area requiring change of use $\left(\mathrm{km}^{2}\right)$ \\
\hline Change of crop species & Total land area requiring reseeding $\left(\mathrm{km}^{2}\right)$ \\
\hline Decontamination of agricultural land & Total land area requiring decontamination $\left(\mathrm{km}{ }^{2}\right)$ \\
\hline Spreading of contaminated milk / composting & Total amount of milk to be spread $(\mathrm{kg})$ \\
\hline Early removal of crops & Total amount of crops requiring disposal $(\mathrm{kg})$ \\
\hline Manipulation of slaughter times & Additional feed required $(\mathrm{kg})$ \\
\hline Ploughing in of a standing crop & Total land area requiring ploughing $\left(\mathrm{km}^{2}\right)$ \\
\hline
\end{tabular}

(10) Maximum individual worker dose (mSv):

Only for workers, individual and collective doses from other pathways than ingestion are calculated (see separate section).

(11) Collective worker dose (man $\mathrm{mSv}$ ).

(12) Number of workers required (persons).

(13) Resources needed (various units): (see below).

(14) Costs (Euro):

A very simple approach is used for calculating costs associated with countermeasures: The resources required for a countermeasure are multiplied by a cost factor per unit resource and then summed over all countermeasures being implemented. Labour costs (e.g. for workers implementing countermeasures) are not included in the modelling.

The resources calculated depend on the countermeasure being implemented. The resources for each countermeasure option are listed in Table IV. If a combination of two or more countermeasures has been implemented, the resources for all options are given as separate values. Resources are either (a) calculated by multiplying the total area where a countermeasure is implemented by the resource requirements per unit area, (b) derived directly from the amount of food produced or feedstuff required within the area where a countermeasure is implemented, or (c) derived directly from the production area of a food within the area where a countermeasure is implemented. 
Acknowledgement. This work has received partial financial support from the European Commission Sixth Framework Programme (Nuclear Fission/Radiation Protection) under the EURANOS integrated project: European approach to nuclear and radiological emergency management and rehabilitation strategies (Contract No: FI6R-CT-2004-508843).

\section{REFERENCES}

Brown J., Smith K.R., Mansfield P., Smith J. (1997) Models for Decontamination, Relocation and Agricultural Countermeasures in RODOS, Radiat. Prot. Dosim. 73, 75-79.

Council Regulation 87/3954/EURATOM (1987) laying down the maximum permitted levels of radioactive contamination of foodstuffs and feeding stuffs following a nuclear accident or any other case of radiological emergency. Off J Eur Commun L371/11.

Ehrhardt J., Raskob W. (2007) Status of the RODOS system for off-site emergency management after nuclear and radiological accidents and its enhancement under the EURANOS project, IJNGEE 1, 363-371.

Ehrhardt J., Weis A. (2000) RODOS: Decision Support System for Off-site Nuclear Emergency Management in Europe. European Commission, Brussels, Report EUR 19144.

Hoe S., Mc Ginnity P., Charnock T.W., Gering F., Andersson K.G., Astrup P. (2008) ARGOS CBRN Decision Support System for Nuclear and Radiological Emergency Management. In: Proceedings: IRPA 12. The 12th International Congress of the International Radiation Protection Association October 19-24, Buenos Aires, Argentina.

Müller H., Bleher M. (1997) Exposure Pathways and Dose Calculations in RODOS: Improvement of Predictions by Measured Data, Radiat. Prot. Dosim. 73, 75-79.

Müller H., Pröhl G. (1993) ECOSYS-87: A Dynamic Model for Assessing Radiological Consequences of Nuclear Accidents, Health Phys. 64, 232.

Nisbet A.F., Jones A., Turcanu C., Camps J., Andersson K.G., Hanninen R., Rantavaara A., Solatie D., Kostiainen E., Jullien T., Pupin V., Ollagnon H., Papachristodoulou C., Ioannides K., Oughton D. (2009) Generic handbook for assisting in the management of contaminated food production systems in Europe following a radiological emergency v2. EURANOS(CAT1)-TN(09)-01. Available at http://www.euranos.fzk.de.

Raskob W., Gering F., Lochard J., Nisbet A., Starostova V., Tomic B. (2010) Overview and main achievements of the EURANOS project: European Approach to Nuclear and Radiological Emergency Management and Rehabilitation Strategies, Radioprotection 45, S9-S22. 